Original Contribution

\title{
MODIFIED BISMARCK BROWN STAINING FOR DEMONSTRATION OF SOFT TISSUE MAST CELLS
}

\author{
N. Tomov, N. Dimitrov* \\ Department of Anatomy, Faculty of Medicine, Trakia University, Stara Zagora, Bulgaria
}

\begin{abstract}
Bismarck brown staining is a suitable method for demonstration of mast cells in peripheral tissues. However, apart from the intensive color of the mast cell granules, almost no other structures are visible after this staining, which may compromise the results and discourage the investigator. In the present report, we validate the applicability of the Bismarck brown staining of soft tissue and introduce a modification of the method to improve the quality of the histological preparation. Counterstaining with haematoxylin produces specimens with superb contrast and high analytical value. We consider our method involving counterstaining to be superior to the classical Toluidine blue staining, because of the greater contrast of mast cells, which makes evaluation easier, while the preparations are suitable for automated image analysis as well.
\end{abstract}

Key words: Bismarck brown, Toluidine blue, mast cells, rat

\section{INTRODUCTION}

Mast cells are a versatile population of granulocytes, found in virtually all tissues of the body $(1,2)$. Their involvement in innate immunity, immunomodulation, inflammation, allergic reaction, autoimmunity, and wound healing puts them at the focus of study during evaluation of histological alterations in such conditions $(3,4,5)$, both in humans and animal models.

The majority of the histochemical methods for demonstration of mast cells depend on the content of heparin (6) and other glycosaminoglycans in their granules (7). Probably the most commonly employed one is the Toluidine blue staining, which shows the mastocytic granules as metachromatic structures (8), however producing a good amount of background staining of other cellular and extracellular elements (9). Such high signal-to-noise ratio can make evaluation of the resulting histological preparation ambiguous. Furthermore, the contrast of mast cells is often not sufficient for an automated or semi-automated image analysis.

\section{AIM}

The aim of the present study is to validate the

\footnotetext{
*Correspondence to: Nikolay Dimitrov, Department of Anatomy, Faculty of Medicine Trakia University, 11 Armejska Str., 6000 Stara Zagora, Bulgaria, e-mail: nikolaydd@abv.bg
}

applicability of the Bismarck brown staining of soft tissue mast cells by comparing it with the widely accepted Toluidine blue staining method. A modification of the method for improving the results by counterstaining is also proposed.

\section{MATERIALS AND METHODS}

We used tissue obtained from six male rats male Wistar normotensive rats, weighing 220$350 \mathrm{~g}$, which were transcardially perfused with 4\% paraformaldehyde (Sigma, Germany) in phosphate-buffered saline as a part of another experiment. All animal handling was done in strict adherence to governmental (Directive 2010/63/EU of the European Parliament and of the Council of September 22, 2010) and institutional animal care regulations.

Following perfusion, tissue pieces containing skin, subcutis and skeletal muscle were excised and immersed in the same fixative at $4{ }^{\circ} \mathrm{C}$ overnight. The samples were thereafter dehydrated and embedded in paraffin following a standard protocol. Sectioning was done in $5 \mu \mathrm{m}$ serial sections. Adjacent sections were mounted on albumen-gelatine covered slides and processed for Bismarck brown or Toluidine blue staining, alternatively. The staining procedure is described in detail below. For the Bismarck brown staining sections were deparaffinised with xylene and rehydrated to $70 \%$ ethanol. They were subsequently 
immersed in a solution of $500 \mathrm{mg}$ Bismarck brown in $80 \mathrm{ml} \mathrm{96 \%} \mathrm{ethanol} \mathrm{and} 10 \mathrm{ml} 1 \mathrm{~N}$ $\mathrm{HCl}$ for 2 hours at room temperature. Following brief differentiation in $70 \%$ ethanol (3 changes), the sections were transferred to a standard Mayer's haematoxylin solution for counterstaining. After blueing in tap water, sections were dehydrated, cleared in xylene, and coverslipped in Entellan.

For the Toluidine blue staining sections were deparaffinised and rehydrated to distilled water. Staining was achieved by immersing the sections in a $0.5 \%$ Toluidine blue solution in distilled water for a few minutes, under visual control of the staining intesity. Sections were then briefly rinsed in distilled water, then dehydrated, cleared, and coverslipped, as already described.

\section{RESULTS}

Mast cells were observed on all histological specimens. Serial sections confirmed that both staining methods label the same structures. Bismarck brown staining produced intensively brown stained cells (Figure 1A, 1B), however with a rather poor contrast against other structures to the point in which orientation in the slide was virtually impossible. Upon careful observation, it could be demonstrated that the staining is conferred in the cytoplasmic granules of the mast cells, and not elsewhere in mast cells and/or other structures. The modified staining produced similar results, with the addition that the nuclei of all cells were stained by the haematoxylin in its typical hue, so the normal histological structures were clearly distinguishable (Figure 1C, 1D). Due to the significant differences in the spectrum of both stains, distinguishing between mast cells and other cells posed no difficulty for the observer.
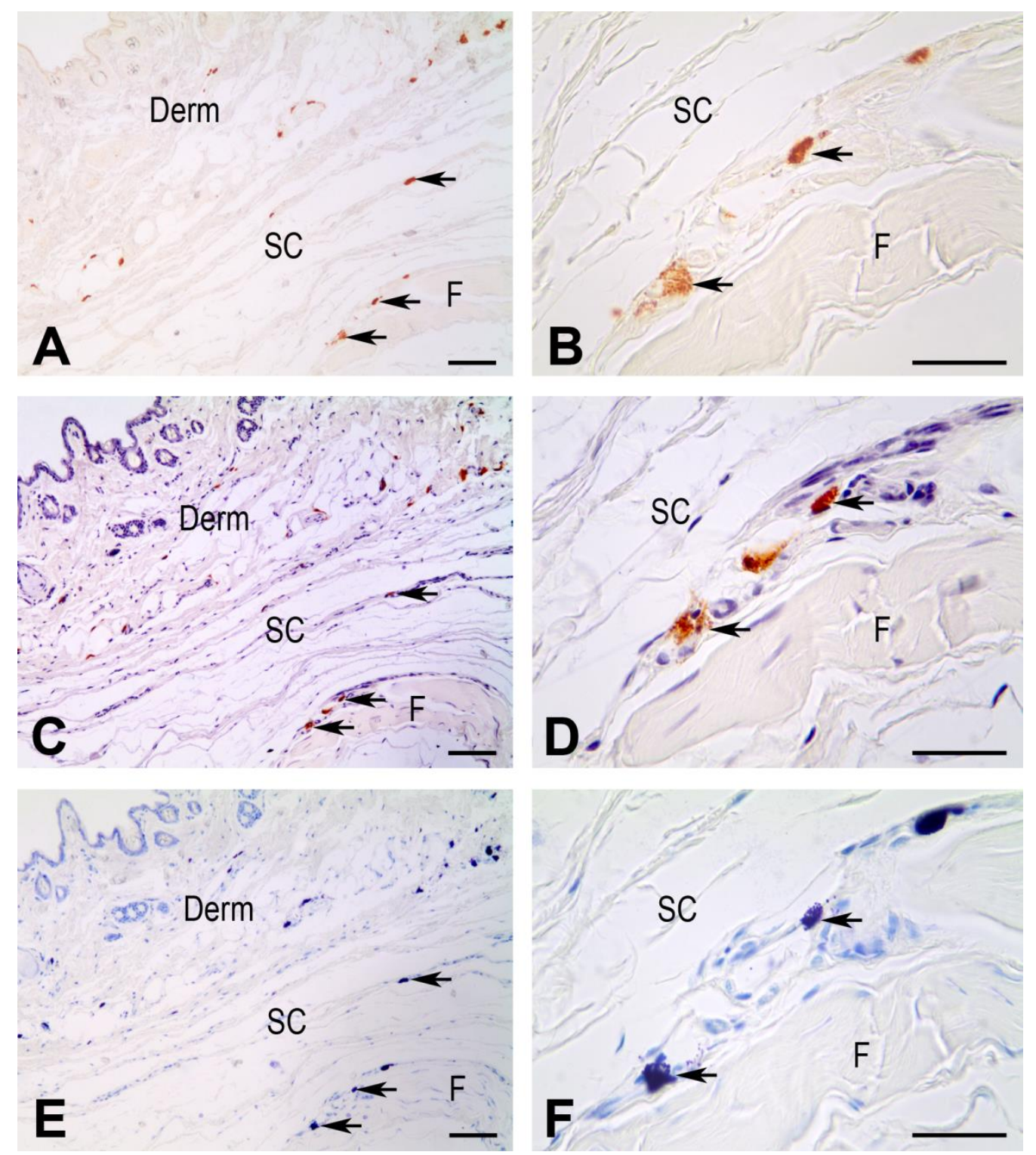

Figure 1. Bismarck brown (A, B), Bismarck brown \& Hematoxylin (C, D) and Toluidine blue (E, F) stained mast cells (arrows) in derma (Derm) and subcutaneous tissue (SC), close to a fascia (F). Scare bar $=50 \mu \mathrm{m}$ 
Toluidine blue stained considerably more structures than Bismarck brown. Mast cells were remarkable for the presence of violet metachromatic cytoplasmic granules, in contrast to the blue stained nuclei of other cells (Figure 1E, 1F). However, the hue of mast cells and other cells was not considerably different, especially when using a solution, which was not prepared ex tempore. In such cases, the only certain criterion to determine a mast cell as such was the granulated nature of its cytoplasm.

\section{DISCUSSION}

In the present study, we verify the Bismarck brown staining to be a viable alternative to the Toluidine blue staining for demonstration of mast cells. Despite this stain was introduced more than 50 years ago (10), it is routinely used in very few experiments $(11,12)$. We attribute this scarcity not to any difficulties in performing the staining procedure, but to the rather poor contrast between mast cells and other tissue elements. To avoid this, we implemented a counterstaining with haematoxylin. Thereby we achieved improved contrast without deterioration of the quality of mast cell labelling. The fact that Bismarck brown and haematoxylin have colour hues on the opposite sides of the visible light spectrum makes their combination quite suitable for subsequent automated image analysis.

We deem our method of counterstaining Bismarck brown to be superior to the Toluidine blue staining, mostly because of the good contrast between mast cells and other cellular elements. Moreover, the results of the staining were quite consistent throughout our experiment, even when the solutions were not freshly prepared. Toluidine blue solution, on the other hand, deteriorated quickly over time, producing highly variable degrees of merachromasia of mastocytic granules.

An important technical detail, which can affect the quality of staining, is the period of fixation of the tissue. Perfusion-fixed and quickly processed tissue specimens from experimental animals showed superb staining. On the contrary, tissue from cadavers used in routine dissection and fixed for several months stained poorly. Interestingly, this was valid for both Bismarck brown and Toluidine blue. It seems that the contents of cytoplasmic granules change over time, making binding with the dye impossible.

\section{CONCLUSION}

Bismarck brown staining can be successfully used for visualization of soft tissue mast cells. Counterstaining with haematoxylin produces specimens with superb contrast and high analytical value.

\section{REFERENCES}

1. Polyzoidis, S., Koletsa, T., Panagiotidou, S., Ashkan, K., Theoharides, T.C., Mast cells in meningiomas and brain inflammation. J Neuroinflammation 12:170, 2005.

2. Miller L., Whitting H.W., Mast cells and wound healing of the skin in the rat. Z. Zellforsch Mikros. Anat 65:597-606, 1964.

3. Metcalfe D.D., Baram D., Mekori Y.A., Mast cells. Physiol Rev 77:1033-1079, 1997

4. Da Silva E., Jamur M., Oliver C., Mast cell function: a new vision of an old cells. $J$ Histochem Cytochem 62:698-738, 2014.

5. Theoharides, T.C., Valent, P., Akin. C., Mast cells, mastocytosis and related diseases. New Engl J Med 373:163-72, 2005.

6. Stefanov I, Vodenicharov A., Tsandev N., Sevrieva D., Histochemical Study of Heparin-positive Mast Cells in the Terminal Part of Porcine Ductus Choledochus and Papilla Duodeni Major, Anat Histol Embryol, 45:1-6, 2015.

7. Simoes, J.P., Schoning, P., Canine mast cell tumors: a comparison of staining techniques. $J$ Vet Diagn Invest 6:458-465, 1994.

8. Vodenicharov A., Endothelin positive mast cells in porcine renal artery and vein. Anat Histol Embryol 37:376-379, 2008.

9. Takahashi, N., Tarumi, W., Hamada, N., Ishizuka, B., Itoh, M.T., Cresyl Violet Stains Mast Cells Selectively: Its Application to Counterstaining in Immunohistochemistry. Zoolog Sci 34:147150, 2017.

10.Spatz, M., Bismarck brown as a selective stain for mast cells. Tech Bull Regist Med Technol, 30:141-143, 1960.

11.Meggers, D.E., Allen, A.M., Feulgen reaction-Bismarck brown; a stain for mast cells in mitosis. Stain Technol, 37:221-223, 1962

12.El Safoury, O.S., Fawzy, M.M., El Maadawa, Z.M., Mohamed, D.H. Quantitation of mast cells and collagen fibers in skin tags. Indian $J$ Dermatol, 54:319-322, 2009. 